\title{
EDITORIAL
}

\section{Critical illness, disability, and the road home}

\author{
Linda Denehy ${ }^{1}$ and Catherine L. Hough ${ }^{2 *}$
}

(C) 2017 Springer-Verlag GmbH Germany, part of Springer Nature and ESICM

\begin{abstract}
Ability to participate in the community is an important outcome for all patients after a major illness, it signposts reaching the end of the road home. A patient's ability to return to the priority tasks of daily living impacts their satisfaction with life, their carers, their family and ultimately the health system [1]. A large body of literature has demonstrated that long term impairments of physical, mental health and/or cognitive domains affect most survivors of critical illness [2,3]. Post-intensive care syndrome (PICS) [4] was developed in 2011 as a framework in which to describe these sequelae. Additionally, it was suggested that these domains be mapped to the World Health Organization (WHO) International Classification of Functioning Disability and Health (ICF) [5], in order to understand impacts on biological, functional, and social levels, and on quality of life. Clinicians, researchers, patients and communities are now working together to try and decrease impairment and quicken the journey of recovery. But what should we measure to enable us to best implement supportive and transformational care for our patients after discharge?
\end{abstract}

It is through this lens that we consider a paper recently published in Intensive Care Medicine. Hodgson and colleagues describe the use of the World Health Organization Disability Assessment Schedule 2 (WHO-DAS) in survivors of critical illness, connecting the dots between measures of impairment and measures of function through assessment of disability [6]. Disability is a complex phenomenon, an overarching concept reflecting the interaction between the environment and the person [7]. It maps across all areas of the ICF and can be measured using the WHO-DAS instrument, a composite tool that

\footnotetext{
*Correspondence: cterrlee@uw.edu

${ }^{2}$ Division of Pulmonary, Critical Care and Sleep Medicine, Harborview Medical Center, University of Washington, Mailstop 359762, 325 Ninth Avenue, Seattle, WA 98122, USA

Full author information is available at the end of the article
}

encompasses six domains of functioning including cognition, mobility, self -care, interactions with people, life activities and participation in the community. Using this instrument, the authors found that $25 \%$ of a critical care population at 6 months suffered moderate to severe disability, associated with inability to return to previous activities such as work and education, and reduced health related quality of life, as assessed by the EQ-5D. They conclude that "disability, measured using the WHO-DAS 2.0 (12 level), is an important outcome following critical illness and should be considered in a core outcome set for ICU research."

So where does measurement of disability fit within a critical care framework? A plethora of different domains of outcome instruments are currently used to assess long term outcomes across the critical care continuum. Recently a core set of outcome measures was developed using rigorous methodology $[8,9]$. The "what" to measure identified eight domains, including HRQoL expressed as satisfaction with life and personal enjoyment. The "how" to measure this domain reached consensus as using the EQ-5D and SF-36v2. The WHO-DAS measure of disability was suggested by participants for rating in the second round of the Delphi, but less than $30 \%$ of the panel members (including patients and caregivers) agreed it was critical for inclusion in the resulting core set of measures. Whether this was the result of lack of understanding of the concept of disability, lack of familiarity with the tool, lack of previous exposure in the ICU population or lack of specificity as a composite measure, is unknown. Certainly there are no data that support the clinimetric properties of this measure for use in critical care populations. Furthermore, reliability and validity of using proxy measures during a critical care admission have yet to be established although research in other populations supports this method of administration. These data are particularly pertinent in ICU for acquiring baseline data to

\section{Springer}


enable longitudinal comparison, although Hodgson et al. did not measure disability at baseline which would have been valuable for assessing trajectories [10].

Could the WHO-DAS short version (12) be best used as a screening tool? It is relatively simple and short to administer. If disability exists then further testing using the longer WHO-DAS with complex scoring or other core outcome measures could be used to tease out the individual domains that require intervention or support. An illustration of a possible road map for patients after an ICU admission, measuring disability as an outcome is depicted in Fig. 1. The composite nature of the WHODAS 12 tool and overall score precludes designing individualized rehabilitation or support since similar scores do not discriminate between the domains that may be worst affected for each patient. Those with acquired moderate to severe disability likely warrant further detailed assessment to determine exact impairment, e.g., physical function, cognitive deficit, and psychological symptoms. These impairments can then be measured, compared with baseline, and targeted interventions developed. Additionally, understanding pre-ICU impairments may provide opportunities to tailor treatments and anticipate setbacks. For example, a study of elderly ICU patients found that vision and hearing impairment were major factors accounting for post-discharge disability [11].

In order to develop and road-test interventions to reduce disability after critical illness, we must understand which patients are at highest risk and the mechanisms that affect prevention or progression. This investigation thoughtfully identified factors associated with moderate/ severe disability-history of anxiety or depression, marital status of separated or divorced, mechanical ventilation duration, and discharge to post-acute care facility rather than home. While interesting, these factors provide little guidance in targeting interventions to those who most need it. Nearly half of those with disability did not have

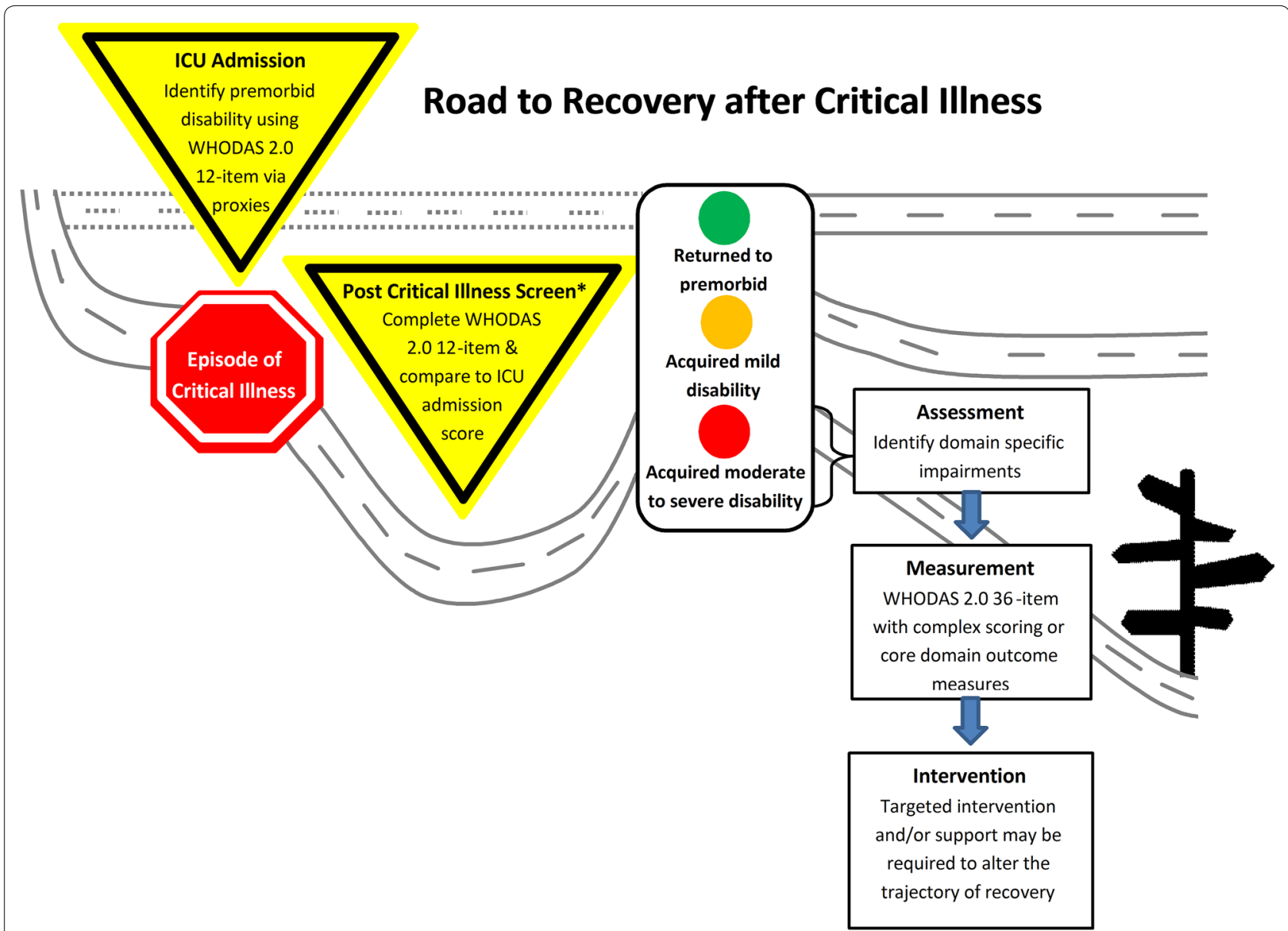

Fig. 1 A schematic road map depicting potential recovery after critical illness according to disability status. A proposed journey for a patient experiencing an episode of critical illness if using the WHODAS disability measure, with three possible recovery trajectories elucidated from screening using the WHODAS. Disability status is determined from comparison of baseline (ICU admission) and post critical illness screening at 3 months 
pre-ICU anxiety or depression, nearly three-quarters of disabled patients were not divorced or separated, and the median duration of mechanical ventilation was short and similar between disability groups-3-4 days. Even destination of discharge-a factor closely tied to patients' ability to care for themselves and engage with their environment-was an imperfect predictor of disability in this cohort. It seems unlikely that this composite measure, which does not differentiate etiologies of disability, is the right tool to identify new targeted therapies; instead, we will need to continue with more granular work as well. At the same time, there may be mechanisms that affect many aspects of disability which transcend simple biologic pathways-such as depression and social support-supporting the approach of using both general and specific measures of disability and functional impairment [12].

How then do we best map a patient's progression from ICU into the community? Is assessment of disability status a robust option to further our field? From a patient and family perspective development of new, or worsening of pre-existing, disability after a critical care stay seems intuitive to be of concern/must surely matter. The method we use to measure this may be critical in driving the types of intervention and support patients may need. Importantly, targeting the patients and families who require the most support should be a priority. Hodgson and colleagues provide us with an alternative route for assessing all three domains of the ICF in one measure of disability. The domains of measurement included within the WHO-DAS resonate with patients, family and clinician researchers with agreement that physical and cognitive function, mental health and return to work should be the most important co-ordinates assessed on the road map to recovery [13]. However, we still have more to do to understand the applicability of the WHO-DAS measure. Moving forward on the measurement of disability determining how it is best measured, and if it best reflects a measure of improvement may be a useful side trip for the field of critical care on our journey to improve long-term outcomes.

\section{Abbreviations}

ICU: intensive care unit; WHODAS: World Health Organisation Disability Assessment Schedule.

\footnotetext{
Author details

1 School of Health Sciences, The University of Melbourne, Level 6, Alan Gilbert Building, Parkville, Melbourne 3010, Australia. ${ }^{2}$ Division of Pulmonary, Critical Care and Sleep Medicine, Harborview Medical Center, University of Washington, Mailstop 359762, 325 Ninth Avenue, Seattle, WA 98122, USA.
}

\section{Acknowledgements}

We are grateful to Jennifer Jones, PhD candidate, Department of Physiotherapy, University of Melbourne for producing the figure.

\section{Compliance with ethical standards}

\section{Conflicts of interest}

The authors have no relevant conflicts of interest.

Received: 1 September 2017 Accepted: 14 September 2017

Published online: 22 November 2017

\section{References}

1. Kress JP, Herridge MS (2012) Medical and economic implications of physical disability of survivorship. Semin Respir Crit Care Med 33:339-347

2. Herridge MS, Tansey CM, Matte A, Tomlinson G, Diaz-Granados N, Cooper A, Guest CB, Mazer CD, Mehta S, Stewart TE, Kudlow P, Cook D, Slutsky AS, Cheung AM (2011) Functional disability 5 years after acute respiratory distress syndrome. N Engl J Med 364:1293-1304

3. Herridge MS, Moss M, Hough CL, Hopkins RO, Rice TW, Bienvenu OJ, Azoulay E (2016) Recovery and outcomes after the acute respiratory distress syndrome (ARDS) in patients and their family caregivers. Intensive Care Med 42:725-738

4. Needham DM, Davidson J, Cohen H, Hopkins RO, Weinert C, Wunsch H, Zawistowski C, Bemis-Dougherty A, Berney SC, Bienvenu OJ, Brady SL, Brodsky MB, Denehy L, Elliott D, Flatley C, Harabin AL, Jones C, Louis D, Meltzer W, Muldoon SR, Palmer JB, Perme C, Robinson M, Schmidt DM, Scruth E, Spill GR, Storey CP, Render M, Votto J, Harvey MA (2012) Improving long-term outcomes after discharge from intensive care unit: report from a stakeholders' conference. Crit Care Med 40:502-509

5. World Health Organization (2001) International classification of functioning, disability and health: ICF. World Health Organization, Geneva

6. Hodgson CL, Udy AA, Bailey M, BarrettJ Belomo R, Bucknall T, Gabbe BJ et al (2017) The impact of disability in survivors of critical illness. Intensive Care Med 43:992-1001. https://doi.org/10.1007/s00134-017-4830-0

7. World Health Organization (2017) Disabilities. http://www.who.int/topics/ disabilities/en/

8. Needham DM, Sepulveda KA, Dinglas VD, Chessare CM, Friedman LA, Bingham CO 3rd, Turnbull AE (2017) Core outcome measures for clinical research in acute respiratory failure survivors: an International Modified Delphi Consensus Study. Am J Respir Crit Care Med 196:1122-1130

9. Turnbull AE, Sepulveda KA, Dinglas VD, Chessare CM, Bingham CO 3rd, Needham DM (2017) Core domains for clinical research in acute respiratory failure survivors: an International Modified Delphi Consensus Study. Crit Care Med 45:1001-1010

10. Iwashyna TJ, Netzer G, Langa KM, Cigolle C (2012) Spurious inferences about long-term outcomes: the case of severe sepsis and geriatric conditions. Am J Respir Crit Care Med 185:835-841

11. Ferrante LE, Pisani MA, Murphy TE, Gahbauer EA, Leo-Summers LS, Gill TM (2016) Factors associated with functional recovery among older intensive care unit survivors. Am J Respir Crit Care Med 194:299-307

12. Cox CE, Porter LS, Hough CL, White DB, Kahn JM, Carson SS, Tulsky JA, Keefe FJ (2012) Development and preliminary evaluation of a telephonebased coping skills training intervention for survivors of acute lung injury and their informal caregivers. Intensive Care Med 38:1289-1297

13. Dinglas VD, Chessare CM, Davis WE, Parker A, Friedman LA, Colantuoni E, Bingham CO, Turnbull AE, Needham DM (2017) Perspectives of survivors, families and researchers on key outcomes for research in acute respiratory failure. Thorax. https://doi.org/10.1136/thoraxjnl-2017-210234 